\title{
Workforce education diversity, work organization, and innovation propensity
}

\author{
Alejandro Bello-Pintado \\ Public University of Navarre -Campus Arrosadía, s/n, Navarre, Spain \\ alejandro.bello@unavarra.es (corresponding autor) \\ Carlos Bianchi \\ Universidad de la República, Facultad de Ciencias Económicas, \\ Instituto de Economía, Uruguay. \\ cbianchi@iecon.ccee.edu.uy
}

\begin{abstract}
Alejandro Bello-Pintado is Associate Professor at the Pubic University of Navarra and researcher of the Institute for Advanced Research in Business and Economics (Inarbe). Engineer, Master in Management and $\mathrm{PhD}$ in Economics, one of his main research areas are the determinants and effects of organizational innovation and its relationship with technological change. He has several articles published in indexed journals, many of them of first quartile in business and economics.
\end{abstract}

Carlos Bianchi received his $\mathrm{PhD}$ in Economics at Federal University of Rio de Janeiro, Brazil. Currently, he holds a position as Associate Professor at the Institute of Economics of University of the Republic (UDELAR), Uruguay. His main research lines are: science, technology and innovation policies, innovative performance and structural change in Latin American economies and health innovation pathways. He is a teacher on undergraduate and graduate programs at UDELAR and has several academic publications on his research areas. 


\section{Abstract}

Purpose

Diversity of people, knowledge, and resources has been identified as a determinant of firms' growth. This paper focuses on innovation propensity as a critical dimension of firm's growth path, aiming to analyse the effects of the firm's horizontal educational diversity (HED) on the propensity to conduct different technological innovation activities (TIAs). In addition, considering the evidence showing that these effects are neither direct nor linear, we analyse the moderating role of the firm's organizational practices oriented to knowledge sharing (KS) on the association between HED and the adoption of TIAs.

Design/methodology/approach

Following the theoretical arguments of the resource based view (RBV), the evolutionary economics and the dynamic capabilities approach and related empirical evidences, we propose four hypothesis regarding the effect of HED on TIAs and the moderating role of work organization practices oriented to promote KS. Empirically, we calculate different HED diversity indexes capturing two basic dimensions: variety and balance. Hence, using instrumental variables and panel data techniques to control endogeneity biases, we test the hypothesis proposed using a dataset of Uruguayan manufacturing firms between 2004 and 2015.

\section{Findings}

In line with previous evidence, results show idiosyncratic context effects. We found a robust, linear, positive, and significant relationship between HED and TIAs, but the effect can be only consistently associated with the adoption of internal or external R\&D activities. Moreover, the moderating role of work organization practices oriented to promote KS is positive and significant when firms engage in TIAs. For technological innovations that only involve the acquisition of new technologies, a positive effect is also observed but always associated to organizational practices oriented to promote KS.

Originality/value

This paper revisits the analysis of workforce diversity for a relatively less explored context. Our research contributes to the field by linking HED and work organization practices, to understand firm's innovation propensity in a developing context. Moreover, while other studies have focused only on top management or R\&D team diversity, we analyse the whole professional's workforce. It allows us to discuss the effects of diversity on innovation propensity in the light of the ongoing debate on the effects of innovation in employment.

Keywords: workforce diversity; technological innovation; work organization; Latin America

JEL codes: O32 M14 L60 


\section{Introduction}

A rich, extensive, and growing research background on the determinants of firms' innovation propensity has been accumulated since the second half of the 20th century. Research on the topic has been mostly focused on the role of competition and appropriability (Cohen, 2010), the effects of innovation experience and learning (Cohen and Levinthal, 1990; Arrow, 1962), and several observable characteristics of the firms (e.g. size, age, sector of activity, and R\&D investment) (Ahuja et al., 2008). However, the roles of people and the way they organize the work inside the firms, as an explanation of innovation propensity, had received relatively less attention from economic researchers until more recent management research contributions were integrated (Nelson, 1991; Laursen and Foss, 2003; Bloom and Van Reenen, 2010).

In this context, workforce diversity, e.g. in gender, age, national origin, and educational background, has recently emerged as a subject of intense study to explain firm innovation propensity (Laursen et al., 2005; Shore et al., 2009; Bell et al., 2011; GarcíaMartínez, et al., 2017; Bolli et al, 2018; Bogers et al., 2018; Bae and Han, 2019). Nevertheless, empirical evidence analysing the effects of workforce diversity on the technological innovation activity of firms is far from conclusive (Lund and Gjerding, 1996; Ozgen et al., 2017; Lee and Walsh, 2016).

This paper aims to contribute to this field analysing the effects of firms' workforce horizontal educational diversity (HED) on the propensity to perform technological innovation activities (TIAs). In doing so, we distinguish TIAs between those based on acquisition of technology (AT) from those based in internal or external research and development (R\&D).

The level and type of education of the workforce are critical knowledge sources and 
therefore, a key resource to overcome innovation barriers (D'Este et al., 2014; Barth et al. 2017). However, while according to some previous research, educational diversity increases the knowledge base of the firms (e.g. Østergaard et al., 2011; Parrotta et al., 2014), other works have shown that workforce diversity also implies a challenge for firms' organization, since it might lead to growing transaction costs, conflict, or distrust among the employees (e.g. Shore., et al., 2009; García-Martínez et al., 2017). Hence, the observation of nonconclusive evidence regarding the link between HED and TIAs claims for considering the existence of moderating factors which, in turn, may improve the understanding of the issue. In this sense, the structure and the way people is organized in the firm may be an enabling factor for employees to use knowledge in a transformative way (Faems and Subranamian, 2013; Camison and Villar-Lopez, 2014).

For instance, it has been stated that decentralised knowledge management practices are positively associated with the effective execution of TIAs (Lund, 1996; Laursen and Foss, 2003); complex problem-solving processes require integrative formal knowledge (Lundvall \& Johnson, 1994), which in turn facilitates the search for and processing of information (Dahlin et al., 2005). These evidences give support to a quite intuitive conjecture: for people to apply knowledge in a creative way they must have opportunities to do so (Hao et al., 2012). To shed new light on this point, this study considers the moderating role of organizational practices oriented to promote knowledge sharing $(\mathrm{KS})$ on the relationship between workforce educational diversity and the firm's TIAs propensity. Following the theoretical arguments of the resource base view (RBV) and the evolutionary economics, we use the concept of dynamic capabilities to understand the relationship between workforce diversity and innovation propensity as a dynamic process associated to the organizational practices followed by the firm (Teece et al., 1997; Teece, 2017). 
The paper contributes to the related literature in several ways. First, we carried out a firm-level analysis that considers the composition of the firm's entire professional workforce rather than just the top management or the R\&D team, typically used in previous studies on workforce diversity (Dahlin et al., 2005; Bell et al., 2011; García-Martínez et al., 2017; Bae and Han, 2019). In addition, we shed light on the relevance of work organization practices allowing firms to recombine its resources and exploit the benefits of KS between diverse employees.

Second, in spite of the long research tradition on innovation, industry, and development in Latin America, there has been hardly any research on workforce diversity and firm innovation (Gallego and Gutiérrez, 2018; Ruiz-Mejías and Corrales-Mejías, 2015). Expanding the evidence on firms' innovation patterns and the role of the workforce qualification in Latin America is particularly relevant seeing the current debate on the creative and destructive effects of innovation on employment (e.g. Aldieri and Vinci, 2018; Crepi et al., 2019).

In addition, this research contributes to understand a complex relationship between the workforce qualitative attributes and the innovation behaviour of the firms in a developing context. In doing so, we follow an empirical strategy using panel data from the Uruguayan Innovation Survey of the manufacturing industry (2004-2015). The survey also covers different organizational characteristics of firms such as structure, hierarchies, and mechanisms adopted to promote participation and working groups. Using different HED's measures to check robustness, our results show coherent but quite different results that most empirical background on the topic. In line with previous research, we found a significant relationship between HED and TIAs, but the effect can be only consistently associated with the adoption of $\mathrm{R} \& \mathrm{D}$ activities. 
For technological innovations that only implicate the acquisition of new technologies (AT) a positive effect of HED is observed when the firm also conduct organizational practices oriented to $\mathrm{KS}$. In this regard, the moderating role of $\mathrm{KS}$ practices is positive and significant when firms engage in TIAs.

This results suggest that innovation strategies integrating R\&D are more challenging in terms of knowledge base as stated recently by Bello-Pintado and Bianchi (2020), and shed some new light to explain why firms adopt innovation strategies that in the most cases only are in the form of technology acquisition as usually happens in less developed contexts (Crespi et al., 2019; Dutrenit et al., 2019).

The paper is organized as follows. In next section we present the theoretical framework and develop the research hypotheses. In section 3, we expose the methodology and detail the empirical approach. In section 4 our findings are presented, to give the final discussion in section 5 .

\section{Theoretical Framework}

Understanding complex concepts and how they are related demands the consideration of broad and varied theoretical perspectives (Yang and Konrad, 2011). Following this assertion, we revisit the main postulates on the relationship between workforce diversity and innovation propensity from the resource-based view (RBV) and evolutionary economics, while discussing the sign and the intensity of this relationship according to other theoretical interpretations such as social categorization and transaction cost theory (Schneider and Northcraft, 1999).

The contribution of a synthesis between these streams of literature has been early stressed (Montgomery, 1995), identifying that they share a dynamic view of the firm, but also 
weaknesses and strengths that complement each other (Nelson, 1991; Foss et al., 1995). Early evolutionary economics offered a dynamic explanation for industrial and technological evolution, highlighting the high diversity among firms' behaviours and performances due to strategic decisions (Levinthal, 1995). However, further evolutionary approaches have been benefitted by the contributions of strategic management studies focused on the internal firm's resources (Nelson, 1991; Laursen and Foss, 2003).

In this sense, the seminal Penrosean concept of firms as dynamic resource collection allows identifying the knowledge diversity embodied in people - educational tenure - as a critical resource that determines the firms' growth trajectory according to its organizational work practices. In this view, employees' tacit and codified knowledge can trigger a competitive strategy based on specific and hardly imitable assets (Penrose, 1959; Wernerfelt, 1984; Grant, 1996). Educational diversity increases the knowledge base of the firm by allowing different knowledge resource combinations according to the firm's requirements. In turn, these potential combinations contribute to developing distinctive capabilities, for instance, identifying and exploiting new and different sources of information (Zahra and George, 2002). Following this reasoning, diversity in a firm's cognitive base increases the ability to exploit knowledge from internal and external sources (Cohen and Levinthal, 1990; Østergard et al., 2011).

Close to this view, one of the basic building blocks in evolutionary economics and management studies states that diversity of agents and knowledge determines the competition in an evolutionary selection process (Metcalfe, 2001). Firms' survival will depend on the ability to reduce the environmental uncertainty by creating routines, which mobilize the firm's internal competencies in a problem-solving path (Malerba and Orsenigo, 2000). In that sense, this stream of literature highlights that workforce diversity expands the internal competencies 
of the firm by broadening internal points of view (Lundvall and Johnson, 1994). Moreover, the relation between workforce composition and the ability to deal with an uncertain environment is one of the key distinctive features that motivate firms to develop different organizational ways associated with their business strategy (Nelson, 1991).

The concept of dynamic capabilities contributes to the matching of these theoretical streams by considering how firms use and combine different resources (capabilities) in a dynamic way, where internal mechanisms operate inside the firms in an evolutionary process, dynamically selecting different resource combinations across time (Teece, 2017).

Nevertheless, the association between educational diversity and the propensity to innovate can be controversial. According to transaction cost theory, workforce diversity may lead to an increase in transaction costs related to communication and coordination of a heterogeneous workforce (Williamson, 1981), which is particularly relevant when related to TIA that itself demands complex governance structures (Sinha, 2019). In this line, similarityattraction theory (Horwitz, 2005) points out that diversity may run contrary to the effectiveness of the group because individuals who are more similar are supposed to be more effective when working together. As a result, workers are aligned along social identity in a way that might cause conflict when a large number of different professional categories and viewpoints coexist (Schneider and Northcraft, 1999).

\subsection{Workforce educational diversity and innovation: concepts, measures, and evidence}

The concept of workforce diversity embraces different dimensions — variety, balance, separation or disparity — and can be observed according to several attributes such as gender, race, and education (Stirling, 1998; Harrison and Klein, 2007). Following these authors, in this paper we measure diversity as variety and balance in terms of education. Variety refers to 
differences in the composition of attributes (tertiary education in our research) among the members of a given unit (firm). Balance refers to proportional distribution of agents according to attributes (e.g. engineering, live sciences, social sciences). HED is measured by the variety and balance in training according to the discipline of the professional field among those employees who have attained a given educational level (Parrotta et al., 2014; Østergaard et al., 2011).

Empirically, evidence connecting HED and innovation is often focused on the composition of the top management team (Li et al., 2016). Several authors have shown that educational diversity enhances the innovation process by increasing the ability of working teams to integrate different perspectives, creating solutions for complex problems (Bantel and Jackson, 1989; Williams and O'Reilly, 1998; Faems and Subranamian, 2013). From another perspective, Dahlin et al. (2005) showed that educational team diversity provided information-processing benefits that outweighed the limitations associated with social categorisation processes. They also demonstrated, that the relationship between workforce education diversity and innovation propensity to develop internal R\&D is not linear, showing the form of an inverted U. That is, the effects of workforce diversity are positive up to a saturation point, beyond which the organization of a large number of different categories of workers (e.g. professions) may lead to diseconomies of specialisation and higher transaction costs due to asymmetries of information and social conflicts. This empirical pattern is related to $R \& D$ internal activities, but not necessarily from the saturation point will a company reduce the propensity to innovate.

H1a. There is a positive association between HED and the propensity to adopt TIAs. 
The adoption of TIAs involve different activities, with different levels of complexity and knowledge requirements. Innovation activities based on the purchase of goods and services are relatively less complex and have been the most frequent TIAs in Latin America (Barletta et al., 2016; Dutrénit et al., 2019). On the other hand, innovation activities based on R\&D are less frequent and show higher requirements for workforce qualifications and a significant correlation with employee educational attainment (Zuniga and Crespi, 2013). In this sense, several scholars have suggested that the creativity benefits of diversity are more relevant for the generation of new knowledge than the cost of coordination and communication affecting the general functioning of diverse organizations (Bogers et al., 2018; García-Martínez et al., 2017; Ruiz-Mejías and Corrales-Mejías, 2015; Østergaard et al., 2011). Therefore, it is expected to observe a differentiated effect of HED on innovation propensity according to the type of TIA considered.

In order to shed new light in this issue, in this paper we distinguish TIAs between those based on acquisition of technology (AT) from those based on R\&D activities (both internal and external). In this line, Williams and O'Reilly (1998) had early noted that the positive effects of employee diversity on the innovation process are associated with the initial steps (creative, searching, etc.) when R\&D activities are highly required. Nevertheless, they even highlighted that diversity has potential negative effects after the search phase, when solutions are just implemented. These results have recently been confirmed, related to vertical educational diversity and innovation propensity (Bolli et al., 2018). As a result, we expect that firms that conduct R\&D, which usually are concentrated in the creative and searching phases, will present a more intensive relationship between HED and innovation propensity than technologically innovative firms that conduct TIAs in the form of acquisition of machinery but do not conduct R\&D activities. 
H1b. The positive association between HED and the propensity to adopt TIAs is higher for adopting $R \& D$ than for AT activities.

\section{2 The moderating role of work organization practices}

Work organization is the result of a continuous process of incorporating organizational innovations that ultimately change the way the work is regularly organized in form of routines, that are more or less explicit practices stipulated in the firm's functioning (Teece, 1992). Evidences support that horizontal work organization practices (e.g. reducing hierarchical levels; promoting employee participation in the decision making) facilitate the exploitation of group capacities associated with members' educational backgrounds, which facilitates the application of organizational routines, contributing to building distinctive resources (Camisón and Forés, 2010).

In this paper, we focus on organizational practices that facilitate KS by enhancing intra-organizational coordination and cooperation between employees with different profiles and positions (Teece, 1992; Love and Roper, 2004), which, in turn create an appropriate environment for innovation to be performed (Damanpour and Evans, 1984; Azar and Ciabuschi, 2017). The effects of work organization practices oriented to promote KS on firm's innovation has been largely documented (Laursen and Foss, 2003; Bloom and Van Reenen, 2010; Cohen, 2010). However, the role played by work organization practices on the relationship between HED and innovation propensity is not obvious. On the one hand, the presence of organizational practices facilitating KS between employees of different internal functions and with different educational backgrounds may favour the internal development of innovation (Kochan et al., 2003; Camisón and Forés, 2010). On the other hand, previous 
studies have also highlighted that horizontal organization practices can trigger negative effects of diversity, mainly after the search phase, when solutions should be implemented, and standardized routines are necessaries (Williams and O'Reilly 1998).

Empirical evidence in the context under study, stated that firms adopting advanced work organization practices are only a small proportion of the total number of firms in the Uruguayan manufacturing sector (Bello-Pintado, 2011). However, he found a positive correlation between advanced organizational forms and performance such as productivity, quality, and innovativeness. This evidence supports the view that in low-development contexts where product and process innovations are widely based on the use of externally acquired technology, the presence of KS work organization practices may favour innovation in products and processes. Therefore, it is expectable that the positive association between HED and innovation propensity will be positively moderated by the presence of organization work practices that favour knowledge sharing. In light of this arguments, we propose the following hypothesis:

H2a. The association between HED and the likelihood of executing TIAs is positively moderated by the presence of organizational practices favouring knowledge sharing.

Regarding horizontal organizational practices and routines, it has been stated that they contribute to exploit the benefits of diversity in initial steps of innovation process, by enabling to overcome potential difficulties in managing a varied skilled workforce (Østergaard et al., 2011). In this line, researchers in the field stressed that organizational practices facilitating KS practices are determinant for the adoption of $\mathrm{R} \& \mathrm{D}$ activities, in particular during the initial steps (Chen and Huang, 2010; Barth et al., 2017). In the background, horizontal organizational 
practices reinforce the absorptive capacities of the firm, facilitating and allowing that people capture and exploit both internal and external information and knowledge (Camisón and Forés, 2010; Bolli et al., 2018).

$H 2 b$. The positive moderation effect of organizational practices favouring $K S$ is higher for the relationship between $H E D$ and $R \& D$ than between $H E D$ and $A T$.

\section{Methods and Data}

The empirical strategy is based on the analysis of a data set from the Uruguayan Innovation Survey (UIS), carried out by the National Institute of Statistics and the National Innovation and Research Agency of Uruguay. The original sample is representative of the whole Uruguayan manufacturing industry, according to activity sector. Information is collected through personal interviews and, since it is an official survey, answers are compulsory for all the sampled firms. This procedure guarantees highly response rates and reliable data.

The UIS questionnaire is based on the Oslo Manual (OECD, 2005) collecting information about a broad set of activities that companies carry out to innovate, before asking whether they achieved innovative results. It is crucial for our research question, which is focused on the propensity to conduct technological innovation activities, not on the propensity to obtain innovation results.

Four waves of the UIS were merged, covering the 2004-2015 period. The structure of the final data set is an unbalanced panel which includes only the firms that were surveyed in at least two waves. This panel includes 2,493 observations from 770 firms (Table 1). 


\title{
Table 1. Structure of the panel
}

\begin{abstract}
About here

\subsection{Variables}

Following the Oslo Manual (OECD, 2005), the UIS examines whether firms have been engaged in technological innovation activities among a list of five activities (Table 2). The UIS also captures whether the firm has implemented practices of work organization such as individual rewards incentives, reduced vertical hierarchies, inter-functional work groups, and communication systems within the firm. In addition, the questionnaire includes information to calculate HED indexes in terms of different professional profiles among the whole organization.
\end{abstract}

\section{Table 2. Summary of variables}

\section{About here}

We consider three dummy dependent variables. First, we distinguish between firms that carried out any of the five TIAs considered and those firms that did not (See Table 2). Second, we distinguish between companies that adopt TIAs that include only the acquisition of capital goods or ICT (AT) from those that conducted internal or external R\&D. Empirical evidence stresses that firms that conduct activities based on $R \& D$ are usually engaged in an innovation strategy that includes acquiring external knowledge (Barletta et al., 2016), although this does not imply a trend in the other direction from knowledge acquisition to R\&D. 
Descriptive figures (Table 5a) show that within the final sample we can find almost $50 \%$ of firms that have conducted at least one TIA, while around $25 \%$ and $20 \%$ have conducted TA and R\&D activities, respectively.

Since diversity does not rely on any structural models of the particular system under study, we used nonparametric measures of diversity, i.e. indexes based on observed distribution of the attribute of interest (Stirling 1998). Moreover, following this author, we measured diversity as an integrative concept that captures variety and balance (Stirling, 1998: 45-57) as non-empirically differentiated attributes.

According to the information available in the UIS database, to measure HED within a firm, we used the information on the disciplinary background of the employees that have attained a tertiary educational level (Tables 2 and 3). The explanatory variable, HED, captures the variety and balance of specific professional profiles. Since on-floor training is not available in the UIS database, this measure captures only the formal training of a particular type of employee and neglects the potential diversity originating from training in the workplace and learning by doing (Jensen et al., 2007).

\section{Table 3. Explanatory variable: diversity indexes}

\section{About here}

Coherently with each index construction, S-W's and Blau's indexes show a similar distribution with high concentration of observations without attributes of interest $(0)$. In this regard, the Simpson index shows a more balanced distribution but with a disproportionate incidence of full diversity. Regarding these descriptive patterns and the related literature, we estimated the effects of the three indexes. However, descriptive statistics aiming to test robustness are in line with Stirling (1998), who concludes that given the usual data restrictions, 
the simpler indexes based on the proportional abundance of the attribute of interest, e.g. Shannon-Weaver and Blau, are preferable to their reciprocal version, e.g. Simpson.

\title{
Figure 1:
}

About here

\section{Table 4. Descriptive statistics for HED indexes vs innovative propensity}

\begin{abstract}
About here
On the other hand, in order to distinguish between the effect of workforce educational level and workforce diversity, we used a specific control variable that indicates whether the firms have at least one professional employee. This is a necessary control because HED indicators are based on count variables of educational attainment, which is directly related to workforce skills and, in turn, is likely related to the decision to engage in TIA (D'Este et al., 2014; Lund, 2006).

Following previous research (Camisón and Villar-López, 2014; Smith et al., 2005; Lund and Gjerding, 1996), to capture the progressive increment in KS work organization practices we built an organizational practices index (OPI). The descriptive statistics indicate that, on average, Uruguayan manufacturing firms have more traditional forms of work organization, with less than $10 \%$ of the sample that fulfils the three KS practices considered (Table 5a).

Our analytical model was completed with five firm-level control variables - size, age, export intensity, foreign capital, and economic group - that have been usually considered as determinants of TIA in the literature from economics and innovation management (Cohen, 2010; Ahuja et al., 2008).
\end{abstract}




\title{
Table 5a Descriptive statistics (categorical variables)
}

\section{About here \\ Table 5b Descriptive statistics (continuous control variables)}

\begin{abstract}
About here

\subsection{Econometric strategy}

We use a probit model to test the effect of HED on the propensity to conduct TIAs. Moreover, following recent contributions on the relationship between educational workforce diversity and firm's innovation behaviour (Østergaard et al., 2011; Secchi et al., 2014; Ozgen et al., 2017; Bolli et al., 2018), we use instrumental variables and panel data techniques (sector and year fixed effects) to control both simultaneity bias and endogeneity problems. This is the best empirical strategy option taking into account the recurrently observed endogeneity problems in the relationship between workforce diversity and innovation, and considering that has not yet been possible to link employer and employee data using the UIS. Hence, we instrumented the independent variable (HED) through its measure one lagged period $\left(\mathrm{HED}_{\mathrm{t}}\right.$ 1), assuring to overcome simultaneity and specific endogeneity problems.
\end{abstract}

Moreover, to control unobservable effects related to firms' idiosyncrasy, we included fixed effects by year of reference of the UIS wave and sector. As usual, using instrumental lagged variables and fixed effects meant losing observations.

$$
P\left(y_{t}=1\right)=\beta_{0}+\beta_{1} I V H E D+\beta_{2}\left(z_{t}\right)+\text { year }+ \text { sector }+\varepsilon_{i t}
$$

where $y$ is the dichotomous independent variable taken at time $t$, HED is instrumented (IV) by $\mathrm{HED}_{\mathrm{t}-1}$, and $(z)$ is a vector of control variables at time $t$. We included fixed effects by year and sector. Finally, $\varepsilon$ is the error term. We included the square of the independent variables to 
test a quadratic (inverted U-shaped) distribution. To test $\mathrm{H} 2 \mathrm{~s}$ we added the organizational practices index (OPI) as well as the interaction term between the independent variables and the OPI, both of them instrumented through a one-period lag observation.

The model was estimated in successive steps, incorporating each variable into each new estimation (Tables 6-8). In addition, in order to compare effects of HED on R\&D propensity and on AT propensity (H1b and $H 2 b)$ we use a standard Z-test (Table 9).

\section{Findings}

Estimation results show that the propensity to adopt TIAs is positive and significantly affected by HED (Table 6). All the three HED indexes positively explain the propensity to conduct TIAs. Thus, empirical estimations support Hla since the greater the HED, the higher the likelihood of conducting TIAs.

\section{Table 6. Estimate results. Dep Var.: Technological Innovation Activities About here}

On the other hand, we considered the presence of a curvilinear relationship between HED and TIAs adoption, and, except in the estimate using Blau's index, we only confirm a linear relationship (Table 6, columns 2, 6, and 10). The interpretation of this result must take into consideration the context under study. Previous empirical works that have observed an inverted U-shaped relationship between diversity measures and firms' performance including innovation propensity, come from Europe (Dahlin et al., 2005; García-Martínez et al., 2017; Bolli et al., 2018) or Asian industrialized countries (Chen and Huang, 2010). The estimates could be indicating that the linear relationship observed may indicate that the level of educational diversity in less developed contexts is low to the extent that the turning point from 
a positive to a negative association is not observed. Therefore, there is no evidence of a fall in the propensity to innovate due to an increase in HED.

To test the hypothesis $H 1 b$, we run two models for each HED index using, on the one hand, the propensity to adopt technological innovations in the form of acquisitions of capital goods or ICT (Table 7), and on the other, the propensity to adopt innovations related with R\&D activities (Table 8).

\section{Table 7 Estimate results: Var. Dep.: Acquisition of technology (Capital goods and/or ICT) About here \\ Table 8. Estimate results: Var. Dep.: Research and Development (R\&D) About here}

Estimates show differentiated effects of HED on the propensity to adopt TIAs regarding the type of innovation activities as stated in $H 1 b$. Estimates in table 7 (Columns 1, 5 and 10) show that - considering the three indexes used- HED affects the propensity to adopt AT, but such effect seems attributable to organizational practices oriented to promote KS are present (Table 7, columns 3, 4, 7, 8 and 10). Meanwhile, as stated in Table 8, HED has a positive, linear and significant effect on the adoption of R\&D activities. Moreover, estimates of the effects of HED on R\&D show a consistent identification of the direction of the relationship, from HED to innovation propensity (Table 8, bottom row shows significant results of Wald exogeneity test). On the contrary, regarding the observed effects of HED on AT, there is no possible to discard endogeneity bias (Table 7, bottom row shows no significant results of Wald exogeneity test).

Despite endogeneity problems, the post-estimation comparison between the effect of HED on R\&D and AT (Table 9), consistently show a stronger effect of HED in the R\&D 
propensity than in the AT propensity. These results confirm that accounting with a broad and varied knowledge base is particularly important for the development of more sophisticated innovation activities than those activities related only with the external acquisition of machinery and ICT. It is also remarkable that for both types of TIAs the U-inverted shape association with HED is not observed (Columns 2, 6 and 10 in Tables 7 and 8), reinforcing the explanation of particular characteristics in less developed context regarding the low level of educational diversity of workforce.

Considering how the organization of work moderates the relationship between HED and the propensity to adopt TIAs, estimates confirm the proposed hypotheses $(H 2 a$ and $H 2 b)$. On the one hand, it is important to highlight that organizational practices oriented to facilitate KS are positively associated with the likelihood of conducting any TIAs (Ccolumns 3, 7 and 11 of Tables 6,7 and 8). On the other hand, results confirm the positive interaction between HED and OPI on the propensity to conduct TIAs (Columns 4, 8 and 12 of Tables 6, 7 and 8). This confirms $H 2 a$, i.e. for diverse people to apply knowledge the way they are organized should give opportunities to do so (Hao et al., 2012).

Regarding $H 2 b$, estimated coefficients shows that, for R\&D activities, the organizational practices oriented to promote KS positively interact with HED to explain the propensity to adopt these innovation activities (Columns 4, 8 and 12 in Table 8). However, as was mentioned above, in the case of AT, results show that the positive effect of HED on the propensity to acquire new machines and ICTs, seems to be attributable to the presence of organizational practices oriented to promote KS (Columns 4, 8 and 12 in Table 7). Finally, post-estimation comparisons (Table 9), show that the moderating effect of OPI on the relationship between HED and R\&D propensity is stronger than on the relationship between HED and AT propensity. 
In sum, this study confirms that having varied educational backgrounds is important for innovation, but also the presence of organizational practices promoting $\mathrm{KS}$ is determinant to innovate (Battisti and Stoneman, 2010; Camisón and Villar-López, 2014). Particularly relevant is the effect of OPI on the propensity to adopt AT since the effect of HED seem to be no relevant in those firms where the organization of work are more traditional.

\section{Final Remarks}

The linkage between the diversity of the internal resources of the firm and the propensity to innovate is in the base of the evolutionary economics and strategic management contributions. Innovative strategies are firm's specific and they emerge from complex interactions between internal and external knowledge. Since deliberated strategies of the firm are not observable, we capture it through the TIAs conducted by the firms, and corroborate the positive relationship between HED and innovation propensity.

Empirical evidence confirms the proposed hypotheses allowing to conclude that the propensity to adopt TIAs is related to the firm's human resources. In particular, we observed that the variety and balance in the knowledge base of firms determine the propensity to adopt TIAs, however, the effect is consistently identified only with the implementation of R\&D activities, while for the acquisition of new machines and ICT do not. In addition, we confirm that organizational work practices aimed to facilitate KS positively interact with HED to determine TIAs.

This paper contributes to academic research by offering theoretical arguments and empirical evidence regarding the relevance of considering innovative capabilities -both at the personal and organization level simultaneously- as part of the resource collection of the firm, that offer different combinations along the growth path of the firm. On the one hand, this paper 
highlights the convenience of considering HED rather than only vertical educational diversity as previously used in related literature (Østergaard et al., 2011; Bolli et al., 2018). In addition, evidence supports the relevance of considering the whole firm's workforce for the adoption of technological innovations rather than only considering top management teams or $\mathrm{R} \& \mathrm{D}$ group members (Li et al., 2016; García-Martínez., et al. 2017). In short, new information and knowledge sources for the development of new products or processes as well as for the identification of the needs of new machines or ICT can be identified and delivered by the whole labor force of the organization. In this sense, our results support that the diversity of educational backgrounds at all organizational levels contributes positively to this process.

On the other hand, the paper analyses the manufacturing industry in a small developing country. The literature from innovation studies has always emphasised the localised nature of innovation and the firm-level specificity of routines, knowledge variety, and organization. However, research in this area has traditionally looked for general patterns, based on theoretical propositions, which help to understand the firm's innovation propensity. These types of patterns, like the saturation effect on absorptive capacities and the consequently inverted U-shaped relationship between educational variety and innovation propensity, did not appear in the Uruguayan context. Therefore, another contribution of the paper is to contrast general premises and evidences from developed countries in a less developed context.

Based on previous evidence on the salient features of firm's innovation behaviour in developing context (Barletta et al., 2016), this paper shows that the effect of HED depends on the type of innovation strategy adopted, i.e. strategies based on R\&D versus those based on technological acquisitions. In this sense, our result suggests that rather than a substitution relationship between these innovation strategies this group of firms shows a sort of integrative strategy, which includes knowledge acquisition embodied in machinery and ICT, and also 
they make innovation based on R\&D. Since our methodology is not adequate to analyse the potential complementary or substitution effects of different TIAs (Ballot et al., 2015), further research may overcome this limitation to shed new light in the role of knowledge diversity embodied in people to pursuit different complementary TIAs.

Finally, our research adds evidence in line with the resource-based view and the evolutionary theory of the firm. The criticism regarding the positive effects of diversity on innovation performance, based on transaction cost theory or the similar attraction theory, does not find empirical support from the results of this study. Therefore, we can interpret our results as evidence for the evolutionary statement that sees diversity as allowing a number of alternative problem-solving ways (routines) that can be dynamically recombined and that operate as strategic assets turning human resources into competitive resources (Teece, 2017).

This paper also has important implications for practitioners and managers, not only for the current Uruguayan context, but also arguably extendable to most Latin American industries. The results of this study highlight the relevance of investing in human resources inside the firm as a determinant of innovation. Typically, highly skilled workers in less developed countries are scarce. According to our results, the challenge for firms is to attract skilled workers with different backgrounds favouring the innovation process. Moreover, our results show that this is a critical resource for companies following innovation strategies based on R\&D activities. On other hand, our results show that companies adopting less intensive innovation activities, specially focused on the acquisition of technology embodied in machines, demand require a relatively less varied knowledge base.

At this point, the most important issue is whether or not the innovation strategy adopted allows firms to be more competitive. In this sense, according with the RBV, the acquisition of new machines, even though it may be important to compete, it is hardly enough 
to do it successfully and to achieve a differentiated competitive advantage; anyone can do the same. Nevertheless, developing new products and processes, exploring new fields of knowledge, which effectively can be decisive to be competitive, can only be achieved in the presence of competitive resources, in this case a wide and varied base of human resources with different point of view and backgrounds. Additionally, this competitive effect can be enhanced when firms are able to accompany these processes with organizational practices that promote worker participation, interaction among different profiles and categories of employees.

This research is particularly timely from the policy-making view. In the light of the current debate on the effects of innovation in employment, we shed light in the complex dynamic of this relationship beyond the short-run substitution or compensation effects that the literature has identified (Aldieri and Vinci, 2018; Crespi et al., 2019). This study highlights the effects of the quality attributes of the firm's workforce as a determinant resource of innovation propensity. It is especially relevant facing the great challenges stated by the current Uruguayan Development Strategy (OPP, 2019) oriented to create employment through structural change based on innovation. Our results, jointly with previous researches (Zuniga and Crespi 2013; Crespi et al., 2019), contribute by stressing the positive effects of innovation in the firm's workforce growth.

The paper presents some limitations. First, one salient contribution of the paper, as the analysis of a small developing country, also limits the potential extrapolation of results. In addition, the relative short time extension of our panel data set, seriously limits potential causal inferences. Finally, but not least, as we already mentioned, further research should consider internal trainee activities and employee mobility by using employer-employee data, to obtain substantive accuracy gains. 


\section{References}

Ahuja, G., Curba, M. and Tandon, V. (2008), "Moving beyond Schumpeter: Management research on the determinants of technological innovation". The Academy of Management Annals, Vol. 2 No. 1, pp 1-98.

Aldieri, L., and Vinci, C. (2018), "Innovation effects on employment in high-tech and low-tech industries: Evidence from large international firms within the triad". Eurasian Business Review, Vol. 8, No 2, pp. 229243.

Arrow, K. (1962), “The economic implications of learning by doing”. The Review of Economic Studies, Vol. 29 No. 3, pp 155-173.

Azar, G. and Ciabuschi, F. (2017), "Organizational innovation, technological innovation, and export performance: The effects of innovation radicalness and extensiveness", International Business Review, Vol. 26, No 2, pp. 324-336.

Bae, S. and Han, S. (2019), "The impact of R\&D workforce diversity on firm's performance in internal and external R\&D", European Journal of Innovation Management. https://doi.org/10.1108/EJIM-09-2018-0204.

Ballot, G., F. Fakhfakh, F. Galia, and A. Salter (2015), 'The fateful triangle: complementarities in performance between product, process and organizational innovation in France and the UK', Research Policy, Vol. 44, No 1, pp. 217-232.

Bantel, K. and Jackson, S. (1989), "Top management and innovations in banking: Does the composition of the top team make a difference?" Strategic Management Journal, Vol. 10, pp. 107-124.

Barletta, F. Pereira, M. Suárez, D. and Yoguel, G. (2016), "Construcción de capacidades en las firmas argentinas. Más allá de los laboratorios de I+ D”. Pymes, Innovación y Desarrollo, Vol 4 No 3. pp. 39-56.

Barth, E. Davis, J. Freeman, R. and Wang, A. (2017), “The Effects of Scientists and Engineers on Productivity and Earnings at the Establishment Where They Work" (No. w23484). National Bureau of Economic.

Battisti, G. and Stoneman, P. (2010), "How innovative are UK firms? Evidence from the fourth UK community innovation survey on synergies between technological and organizational innovations". British Journal of Management, Vol. 21, pp 187-206.

Bell, S. Villado, A. Lukasik, M. Belau, L. and Briggs, A. (2011), "Getting specific about demographic diversity variable and team performance relationships: A meta-analysis". Journal of Management, Vol. 37, pp 709743.

Bello-Pintado, A. and Bianchi, C. (2020) "Consequences of open innovation: effects on skill-driven recruitment”. Journal of Knowledge Management. DOI:10.1108/JKM-08-2019-0437.

Bello-Pintado, A. (2011). Reto de la innovación en la empresa industrial: la experiencia uruguaya, Ediciones Granica. Buenos Aires.

Bloom, N. and Van Reenen, J. (2010), "Why do management practices differ across firms and countries?" Journal of Economic Perspectives, Vol. 24 No. 1, pp. 203-224.

Bogers, M. Foss, N. and Lyngsie, J. (2018), "The 'human side' of open innovation: The role of employee diversity in firm-level openness". Research Policy, Vol. 47, No. 1, pp. 218-231.

Bolli, T. Renold, U. and Wörter, M. (2018), "Vertical educational diversity and innovation performance". Economics of Innovation and New Technology, Vol. 27, No. 2, pp. 107-131.

Camisón, C. and Forés, B. (2010), "Knowledge absorptive capacity: New insights for its conceptualization and measurement". Journal of Business Research, Vol 63, pp. 707-715.

Camisón, C. and Villar-López, A. (2014), "Organizational innovation as an enabler of technological innovation capabilities and firm performance”. Journal of Business Research, Vol 67, pp, 2891-2902.

Chen, C., and Huang, Y. (2010). "Creative workforce density, organizational slack, and innovation performance". Journal of Business Research, Vol. 63, No. 4, pp. 411-417.

Cohen, W. (2010), "Fifty years of empirical studies of innovative activity and performance", in: Hall, B. and Rosenberg, N. (Eds), Handbook of the Economics of Innovation (Vol. 1), Elsevier, Amsterdam. pp. 129-213.

Cohen, W. and Levinthal, D. (1990), "Absorptive-capacity - A new perspective on learning and innovation". Administrative Science Quarterly, Vol. 35, pp. 128-152.

Crespi, G. Tacsir, E. and Pereira, M. (2019), "Effects of innovation on employment in Latin America". Industrial and Corporate Change, Vol. 28, No 1, pp. 139-159. 
Dahlin, K. Weingart, L. and Hinds, P. (2005), "Team diversity and information use". Academy of Management Journal, Vol. 48, No. 6, pp. 1107-1123.

Damanpour, F., and Evan, W. (1984), "Organizational innovation and performance: the problem of" organizational lag", Administrative science quarterly, Vol. 29, No.3, pp.392-409.

D'Este, P. Rentocchini, F. and Vega-Jurado, J. (2014), "The role of human capital in lowering the barriers to engaging in innovation: Evidence from the Spanish innovation survey". Industry and Innovation, Vol 21, No. 1, pp. 1-19.

Dutrénit, G., Natera, J. Puchet, M. and Vera-Cruz, A. (2019), "Development profiles and accumulation of technological capabilities in Latin America". Technological Forecasting and Social Change, Vol. 145, pp. 396-412.

Faems, D. and Subramanian, A. (2013), "R\&D manpower and technological performance: The impact of demographic and task-related diversity". Research Policy, Vol. 42, No. 9, pp. 1624-1633.

Foss, N. Knudsen, C. and Montgomery, C. (1995). An exploration of common ground: Integrating evolutionary and strategic theories of the firm. In: Montgomery, C. (Ed), Resource-based and evolutionary theories of the firm: Towards a synthesis (pp. 1-17). Springer, Boston, MA.

Gallego, J. and Gutiérrez, L. (2018), "An Integrated Analysis of the Impact of Gender Diversity on Innovation and Productivity in Manufacturing Firms" (No. IDB-WP-00003). Inter-American Development Bank.

García-Martínez, M. Zouaghi, F. and García-Marco, T. (2017), "Diversity is strategy: The effect of R\&D team diversity on innovative performance". R\&D Management, Vol. 47, No. 2, pp. 311-329.

Grant, R. (1996), “Toward a knowledge-based theory of the firm”. Strategic Management Journal, Vol. 17 No. S2, pp. 109-122.

Hao, Q. Kasper, H. and Muehlbacher, J. (2012), "How does organizational structure influence performance through learning and innovation in Austria and China". Chinese Management Studies, Vol. 6, No. 1, pp. 3652.

Harrison, D. and Klein, K. (2007), "What's the difference? Diversity constructs as separation, variety, or disparity in organizations". The Academy of Management Review, Vol. 32, No. 4, pp. 1199-1228.

Horwitz, S. (2005), "The compositional impact of team diversity on performance: Theoretical considerations". Human Resource Development Review, Vol. 4, No. 2, pp. 219-245.

Jensen, M. Johnson, B. Lorenz, E. and Lundvall, B.Å. (2007), "Forms of knowledge and modes of innovation". Research Policy, Vol. 36, No. 5, pp. 680-693.

Kochan, T. Bezrukova, K. Ely, R. Jackson, S. Joshi, A. Jehn, K. Leonard, J. Levine, D. and Thomas, D. (2003), "The effects of diversity on business performance: Report of the diversity research network". Human Resource Management, Vol. 42, No. 1, pp. 3-21.

Laursen, K. and Foss, N. (2003), "New human resource management practices, complementarities and the impact on innovation performance". Cambridge Journal of Economics, Vol. 27, No. 2, pp. 243-263.

Laursen, K. Mahnke, V. and Vejrup-Hansen, P. (2005), "Do differences make a difference? The impact of human capital diversity, experience and compensation on firm performance in engineering”. DRUID Working Paper Series 5(4). Copenhagen.

Lee, Y.-N. and Walsh, J. (2016), "Inventing while you work: Knowledge, non-R\&D learning and innovation". Research Policy, Vol. 45, No. 1, pp. 345-359.

Levinthal, D. A. (1995). "Strategic management and the exploration of diversity". In: Montgomery, C. A. (Ed.). Resource-based and evolutionary theories of the firm: Towards a synthesis. Springer, Boston. (pp. 19-42).

Li, C.-R. Liu, Y-Y. Lin, C-J. and Ma, H-J. (2016), "Top management team diversity, ambidextrous innovation and the mediating effect of top team decision-making processes". Industry and Innovation, Vol. 23, No. 3, pp. 260-275.

Love, J. and Roper, S. (2004), "The organisation of innovation: collaboration, cooperation and multifunctional groups in UK and German manufacturing". Cambridge Journal of Economics, Vol. 28, No. 3, pp. 379-395.

Lund, R. (2006), "Absorptive capacity and innovative performance: A human capital approach". Economics of Innovation and New Technology, Vol. 15, No. 4-5, pp. 507-517.

Lund, R. and Gjerding, A. (1996), "The flexible company. Innovation, work organisation and human resource management”. DRUID Working Paper No. 96-17. Copenhagen. 
Lundvall, B.-Ä. and Johnson, B. (1994), “The learning economy”. Journal of Industry Studies, Vol. 1, pp. 2342.

Malerba, F. and Orsenigo, L. (2000), "Knowledge, innovative activities and industrial evolution". Industrial and Corporate Change, Vol. 9, No. 2. pp. 289-314.

Metcalfe, J. (2002), Evolutionary economics and creative destruction. Routledge, London.

Montgomery, C. A. (Ed.). (1995). Resource-based and evolutionary theories of the firm: towards a synthesis. Springer Science \& Business Media. New York.

Nelson, R. (1991), "Why do firms differ, and how does it matter? Strategic Management Journal”, Vol. 12, No. S2, pp. 61-74.

Oficina de Planeamiento y Presupuesto (OPP) (2019) "Hacia una Estrategia Nacional de Desarrollo 2050". Presidencia de la República, Uruguay. Available at: https://www.opp.gub.uy/sites/default/files/documentos/201805/Hacia_una_Estrategia_Nacional_de_Desarrollo_Uruguay_2050-Publicacion.pdf. (Accessed 20 February 2020)

Organisation for Economic Cooperation and Development (OECD) (2005), Oslo Manual - Guidelines for Collecting and Interpreting Innovation Data, OECD, Paris.

Østergaard, C. Timmermans, B. and Kristinsson, K. (2011), "Does a different view create something new? The effect of employee diversity on innovation", Research Policy, Vol. 40, No. 3, pp. 500-509.

Ozgen, C. Nijkamp, P. and Poot, J. (2017), “The elusive effects of workplace diversity on innovation". Papers in Regional Science, Vol. 96, pp. S29-S49.

Parrotta, P. Pozzoli, D. and Pytlikova, M. (2014), "The nexus between labour diversity and firm's innovation", Journal of Population Economics, Vol. 27, No. 2, pp. 303-364.

Penrose, E. (1959), The theory of the growth of the firm. Basil Blackwell, London.

Ruiz-Mejías, K. and Corrales-Mejías, R. (2015), "The Impact of Employee Diversity and Participation on Innovation: A Two-Step Regression Model for the Costa Rican Industrial Sector". 13th GLOBELICS International Conference; Havana Available at: http://www.academia.edu/download/43364077/Diversity_and_Participation_on_Innovation_Ruiz_and_Corrales.pdf. (Accessed 21 October 2019)

Schneider, S. and Northcraft, G. (1999), "Three social dilemmas of workforce diversity in organizations: A social identity perspective". Human Relations, Vol. 52, No. 11, pp. 1445-1467.

Secchi, A. Tamagni, F. and Tomas, C. (2016), "Financial constraints and firm exports: accounting for heterogeneity, self-selection and endogeneity". Industrial and Corporate Change, Vol. 25, No. 5, pp. 813827.

Sinha, K. (2019), "Variety of R\&D governance structures: A transaction cost economics perspective". Academy of Management Proceedings, Vol. 19: 18023.

Shore, L. Chung-Herrera, B. Dean, M. Ehrhart, K. Jung, D. Randel, A. and Singh, G. (2009), "Diversity in organizations: Where are we now and where are we going?" Human Resource Management Review, Vol. 19, pp. 117-133.

Smith, K. Collins, C. and Clark, K. (2005), "Existing knowledge, knowledge creation capability, and the rate of new product introduction in high-technology firms". Academy of Management Journal, Vol. 48, No. 2, pp. 346-357.

Stirling, A. (1998), "On the economics and analysis of diversity". Science Policy Research Unit (SPRU), Electronic Working Papers Series, Paper, 28. Sussex University, Brighton.

Teece, D. (1992), "Competition, cooperation, and innovation: Organizational arrangements for regimes of rapid technological progress". Journal of Economic Behavior \& Organization, Vol. 18, pp. 1-25.

Teece, D. Pisano, G. and Shuen, A. (1997), "Dynamic capabilities and strategic management". Strategic Management Journal, Vol. 18, No. 7, pp. 509-533.

Teece, D. (2017), "Towards a capability theory of (innovating) firms: Implications for management and policy". Cambridge Journal of Economics, Vol. 41, No. 3, pp. 693-720.

Van Beers, C. and Zand, F. (2014), "R\&D cooperation, partner diversity, and innovation performance: an empirical analysis". Journal of Product Innovation Management, Vol. 31, No 2, pp. 292-312.

Wernerfelt, B. (1984), “A resource-based view of the firm”. Strategic Management Journal, Vol. 5, pp. 171180. 
Williams, K. and O'Reilly, C. (1998), "Forty years of diversity research: A review”. In: Staw, B. and Cummings, L. (Eds) Research in Organizational Behaviour, JAI Press, Greenwich, pp. 77-140.

Williamson, O. (1981), "The economics of organization: The transaction cost approach". American Journal of Sociology, Vol. 87, pp. 548-577.

Yang, Y. and Konrad, A. (2011), "Understanding diversity management practices: Implications of institutional theory and resource-based theory". Group \& Organization Management, Vol. 36, No. 1, pp. 6-38.

Zahra, S. and George, G. (2002), "Absorptive capacity: A review, reconceptualization, and extension”. Academy of Management Review, Vol. 27, No. 2, pp. 185-203.

Zuniga, P. and Crespi, G. (2013), "Innovation strategies and employment in Latin American firms". Structural Change and Economic Dynamics, Vol. 24, pp. 1-17.

Table 1. Distribution of dependent variables

\begin{tabular}{lccc}
\hline \multicolumn{3}{c}{ \% of the sample } & Mean \\
Tipp & 89.49 & & 0.89 \\
incremental & 86.40 & 0.86 \\
Radical & 10.40 & & 0.10 \\
\hline \multicolumn{2}{l}{ Source: Authors' calculation based on UIIS data }
\end{tabular}

Source: Authors' calculation based on UIIS data

Table 2. Name and type of variables included in the estimations

\begin{tabular}{lccc} 
Table 2. Name and type of variables included in the estimations & \multicolumn{2}{c}{ Type } \\
\hline \multicolumn{1}{c}{ Variable } & Name & & \\
1. Technological innovation in product or process (TPP) & tipp & Dichotomous & Dependent \\
2. Radical innovation TPP & radical & Dichotomous & Dependent
\end{tabular}




\begin{tabular}{|c|c|c|c|}
\hline 3. Incremental innovation TPP & incremental & Dichotomous & Dependent \\
\hline 4. Blau index professional & Blau_prof & Continuous & Independent \\
\hline 5. Organizational structure index & $O S$ & Additive-Ordinal & Moderating \\
\hline 6. Size firm $(\log )$ & $\operatorname{logSize}$ & Continuous & Control \\
\hline 7. FDI & $F D I$ & Dichotomous & Control \\
\hline 8. Age & $\log$ Age & Continuous & Control \\
\hline 9 Export intensity (\% of total sales) & export & Continuous & Control \\
\hline 10 Dummy of activity sector & & Dichotomous & Control \\
\hline
\end{tabular}

Source: Developed by authors.

Table 3. Descriptive statistics and correlation matrix

\begin{tabular}{|c|c|c|c|c|c|c|c|c|c|c|c|c|c|}
\hline Variable & Mean & s.d. & Min. & Max & $\mathbf{N}$ & 1 & 2 & 3 & 4 & 5 & 6 & 7 & 8 \\
\hline 1. tipp & .8949 & .3069 & 0 & 1 & 875 & 1 & & & & & & & \\
\hline 2. radical & .104 & .3054 & 0 & 1 & 875 & $0.1168^{*}$ & 1 & & & & & & \\
\hline 3. incremental & .864 & .3430 & 0 & 1 & 875 & $0.8640 *$ & $-0.1597 *$ & 1 & & & & & \\
\hline 4. Blau_prof & .5195 & .2097 & 0 & .857 & 689 & 0.0596 & 0.0558 & 0.0699 & 1 & & & & \\
\hline 5. $O S$ & 1.832 & 1.4368 & 0 & 5 & 875 & $0.1052 *$ & $0.1129^{*}$ & 0.0650 & $0.1477 *$ & 1 & & & \\
\hline 6. log_Size & 4.433 & 1.0776 & 2.302 & 7.80 & 875 & $0.0964 *$ & $0.1381 *$ & 0.0586 & $0.3320^{*}$ & $0.2506 *$ & 1 & & \\
\hline 7. $F D I$ & .2023 & .4019 & 0 & 1 & 875 & 0.0520 & 0.0708 & 0.0587 & $0.1699 *$ & $0.2709 *$ & $0.2727 *$ & 1 & \\
\hline 8. $\log \_$Age & 3.2448 & .8334 & 0 & 4.96 & 869 & $0.0945^{*}$ & 0.0622 & $0.0931 *$ & 0.0969 & 0.0653 & $0.2728 *$ & 0.239 & 1 \\
\hline 9. Export & 24.888 & 34.860 & 0 & 100 & 875 & 0.0275 & $0.3004 *$ & -0.0685 & $0.1479 *$ & $0.1810^{*}$ & $0.3547 *$ & $0.3262 *$ & -0.0501 \\
\hline
\end{tabular}

Source: Authors' calculations based on UIIS data

Table 4. Sectoral distribution of observations and correlation matrix

\begin{tabular}{lcc|cccccccccccc}
\hline \multicolumn{1}{c}{ Industry } & $\mathbf{N}$ & $\mathbf{\%}$ & $\boldsymbol{t}$ ipp & radical & incremental & Blau_prof & OS & log_Size & FDI & log_Age & Export \\
Machinery & 58 & 6.63 & -0.0435 & 0.0146 & -0.0417 & -0.0222 & 0.0056 & $-0.1346^{*}$ & $-0.0884^{*}$ & -0.0409 & -0.0716 \\
Textiles & 106 & 12.11 & -0.0440 & 0.0571 & $-0.877^{*}$ & -0.0531 & $-0.1054^{*}$ & 0.0031 & $-0.0998^{*}$ & 0.0311 & $0.1730^{*}$ \\
Wood & 42 & 4.80 & -0.0102 & -0.0590 & 0.0111 & -0.0285 & -0.0594 & -0.0207 & 0.0866 & -0.0615 & 0.0265 \\
Chemical & 234 & 26.74 & 0.0135 & -0.0028 & 0.0213 & 0.0337 & $0.1156^{*}$ & $-0.1180^{*}$ & $0.0878^{*}$ & 0.0730 & $-0.1073^{*}$
\end{tabular}




\begin{tabular}{lrr|rrrrrrrrrr} 
Metallurgy & 69 & 7.89 & 0.0450 & -0.0024 & 0.0419 & -0.0931 & 0.0254 & -0.0558 & -0.0418 & 0.0035 & -0.0530 \\
Food & 298 & 34.06 & -0.0118 & -0.0569 & 0.0155 & -0.1705 & -0.0017 & $-0.1724 *$ & 0.0764 & -0.0415 & $-0.1440 *$ \\
Others & 68 & 7.77 & 0.0262 & 0.0159 & 0.0248 & 0.1584 & -0.0251 & $0.3172 *$ & $-0.1037 *$ & -0.0190 & $0.1182 *$ \\
\hline
\end{tabular}

Source: Authors' calculations based on UIIS data. 
Table 5 Logit model estimation.

Dependent variable: Technological innovation in product or process

\begin{tabular}{ccccccccc}
\hline \multirow{2}{*}{ Blau_prof $(t-1)$} & & $(1)$ & $(2)$ & $(3)$ & $(4)$ & $(5)$ & $(6)$ & $(7)$ \\
& Coef & $2.113^{* *}$ & 2.216 & 2.011 & $1.748^{* *}$ & 1.380 & 1.086 & 0.857 \\
& SE & $(0.840)$ & $(2.439)$ & $(2.299)$ & $(0.782)$ & $(1.079)$ & $(1.121)$ & $(1.107)$ \\
& Margin & 0.0119 & 0.363 & 0.382 & 0.0255 & 0.201 & 0.333 & 0.439 \\
Blau_prof_square (t-1) & Coef & & -0.150 & -0.388 & & & & \\
& SE & & $(3.365)$ & $(3.164)$ & & & & \\
\multicolumn{1}{c}{ OS $(t-1)$} & Margin & & 0.964 & 0.902 & & & & \\
& Coef & & & 0.190 & 0.189 & 0.0933 & 0.0956 & 0.0771 \\
& SE & & & $(0.138)$ & $(0.138)$ & $(0.299)$ & $(0.300)$ & $(0.283)$ \\
& Margin & & & 0.166 & 0.171 & 0.755 & 0.750 & 0.786 \\
& Coef & & & & & 0.232 & 0.219 & 0.317 \\
& SE & & & & & $(0.553)$ & $(0.545)$ & $(0.535)$
\end{tabular}




\begin{tabular}{|c|c|c|c|c|c|c|c|c|}
\hline & Margin & & & & & 0.674 & 0.688 & 0.553 \\
\hline \multirow[t]{3}{*}{$\log \_s i z e$} & Coef & & & & & & 0.115 & 0.0369 \\
\hline & $\mathrm{SE}$ & & & & & & $(0.217)$ & $(0.212)$ \\
\hline & Margin & & & & & & 0.598 & 0.862 \\
\hline \multirow[t]{3}{*}{$F D I(t-1)$} & Coef & & & & & & 0.00502 & -0.0149 \\
\hline & SE & & & & & & $(0.495)$ & $(0.484)$ \\
\hline & Margin & & & & & & 0.992 & 0.975 \\
\hline \multirow[t]{3}{*}{ log_age } & Coef & & & & & & $0.440^{*}$ & $0.430^{*}$ \\
\hline & SE & & & & & & $(0.236)$ & $(0.249)$ \\
\hline & Margin & & & & & & 0.0622 & 0.0846 \\
\hline \multirow[t]{3}{*}{ Export $(t-1)$} & Coef & & & & & & -0.00196 & -0.00195 \\
\hline & SE & & & & & & $(0.00603)$ & $(0.00613)$ \\
\hline & Margin & & & & & & 0.744 & 0.751 \\
\hline \multirow[t]{3}{*}{ machinery } & Coef & & & & & & & -0.892 \\
\hline & SE & & & & & & & $(0.640)$ \\
\hline & Margin & & & & & & & 0.164 \\
\hline \multirow[t]{3}{*}{ textiles } & Coef & & & & & & & -0.206 \\
\hline & SE & & & & & & & $(0.645)$ \\
\hline & Margin & & & & & & & 0.749 \\
\hline \multirow[t]{3}{*}{ wood } & Coef & & & & & & & -0.682 \\
\hline & SE & & & & & & & $(0.566)$ \\
\hline & Margin & & & & & & & 0.228 \\
\hline \multirow[t]{3}{*}{ chemical } & Coef & & & & & & & -0.306 \\
\hline & SE & & & & & & & $(0.516)$ \\
\hline & Margin & & & & & & & 0.552 \\
\hline \multirow[t]{3}{*}{ metallurgy (omitted) } & Coef & & & & & & & - \\
\hline & SE & & & & & & & \\
\hline & Margin & & & & & & & - \\
\hline \multirow[t]{3}{*}{ others } & Coef & & & & & & & -0.879 \\
\hline & SE & & & & & & & $(0.686)$ \\
\hline & Margin & & & & & & & 0.200 \\
\hline \multirow[t]{3}{*}{ Food (omitted) } & Coef & & & & & & & - \\
\hline & SE & & & & & & & \\
\hline & Margin & & & & & & & - \\
\hline Observations & & 469 & 469 & 469 & 469 & 469 & 469 & 441 \\
\hline Cases & & 329 & 329 & 329 & 329 & 329 & 329 & 309 \\
\hline
\end{tabular}


Table 6. Logit model estimation. Dependent variable: Radical innovation

\begin{tabular}{|c|c|c|c|c|c|c|c|c|}
\hline & & (1) & (2) & (3) & (4) & (5) & (6) & (7) \\
\hline \multirow[t]{3}{*}{ Blau_prof $(t-1)$} & Coef & $3.459^{* *}$ & -2.216 & -2.580 & $2.859^{*}$ & -0.543 & -1.309 & -1.447 \\
\hline & SE & $(1.587)$ & (3.553) & (3.638) & (1.532) & (1.693) & $(1.772)$ & $(1.682)$ \\
\hline & Margin & 0.0293 & 0.533 & 0.478 & 0.0621 & 0.749 & 0.460 & 0.390 \\
\hline \multirow[t]{3}{*}{ Blau_prof_square $(t-1)$} & Coef & & 6.637 & 6.428 & & & & \\
\hline & SE & & (4.133) & $(4.223)$ & & & & \\
\hline & Margin & & 0.108 & 0.128 & & & & \\
\hline \multirow[t]{3}{*}{$O S(t-1)$} & Coef & & & $0.442 * * *$ & $0.441^{* * *}$ & -0.576 & $-0.777 * *$ & $-0.806 * *$ \\
\hline & SE & & & $(0.144)$ & $(0.138)$ & $(0.369)$ & $(0.388)$ & $(0.374)$ \\
\hline & Margin & & & 0.00215 & 0.00140 & 0.119 & 0.0449 & 0.0309 \\
\hline \multirow[t]{3}{*}{ Blau_prof* $O S(t-1)$} & Coef & & & & & $1.837 * * *$ & $2.085^{* * *}$ & $2.060 * * *$ \\
\hline & SE & & & & & $(0.690)$ & $(0.702)$ & $(0.642)$ \\
\hline & Margin & & & & & 0.00773 & 0.00296 & 0.00134 \\
\hline \multirow[t]{3}{*}{$\log \_s i z e$} & Coef & & & & & & -0.153 & -0.0394 \\
\hline & SE & & & & & & $(0.239)$ & $(0.235)$ \\
\hline & Margin & & & & & & 0.523 & 0.867 \\
\hline \multirow[t]{3}{*}{$F D I(t-1)$} & Coef & & & & & & -0.933 & -0.947 \\
\hline & SE & & & & & & $(0.627)$ & $(0.593)$ \\
\hline & Margin & & & & & & 0.136 & 0.110 \\
\hline \multirow[t]{3}{*}{ log_age } & Coef & & & & & & 0.409 & 0.309 \\
\hline & SE & & & & & & $(0.432)$ & $(0.450)$ \\
\hline & Margin & & & & & & 0.344 & 0.493 \\
\hline \multirow[t]{3}{*}{ Export $(t-1)$} & Coef & & & & & & $0.0303 * * *$ & $0.0304 * * *$ \\
\hline & SE & & & & & & $(0.00765)$ & $(0.00716)$ \\
\hline & Margin & & & & & & $7.67 \mathrm{e}-05$ & $2.21 \mathrm{e}-05$ \\
\hline \multirow[t]{3}{*}{ machinery } & Coef & & & & & & & 1.166 \\
\hline & SE & & & & & & & $(0.885)$ \\
\hline & Margin & & & & & & & 0.187 \\
\hline \multirow[t]{3}{*}{ textiles } & Coef & & & & & & & 0.0970 \\
\hline & SE & & & & & & & $(0.709)$ \\
\hline & Margin & & & & & & & 0.891 \\
\hline wood & Coef & & & & & & & -0.390 \\
\hline
\end{tabular}




\begin{tabular}{|c|c|c|c|c|c|c|c|c|}
\hline \multicolumn{8}{|c|}{ SE } & $(1.135)$ \\
\hline \multirow{3}{*}{ chemical } & Margin & & & & & & & 0.731 \\
\hline & Coef & & & & & & & 0.645 \\
\hline & SE & & & & & & & $(0.608)$ \\
\hline \multirow{4}{*}{ metallurgy } & Margin & & & & & & & 0.288 \\
\hline & Coef & & & & & & & 0.693 \\
\hline & SE & & & & & & & $(0.871)$ \\
\hline & Margin & & & & & & & 0.426 \\
\hline \multirow[t]{3}{*}{ others(omitted) } & Coef & & & & & & & - \\
\hline & SE & & & & & & & \\
\hline & Margin & & & & & & & - \\
\hline \multirow[t]{3}{*}{ Food (omitted) } & Coef & & & & & & & - \\
\hline & $\mathrm{SE}$ & & & & & & & \\
\hline & Margin & & & & & & & - \\
\hline Observations & & 469 & 469 & 469 & 469 & 469 & 469 & 438 \\
\hline Cases & & 329 & 329 & 329 & 329 & 329 & 329 & 307 \\
\hline
\end{tabular}

Table 7 Logit model estimation. Dependent variable: Incremental innovation

\begin{tabular}{|c|c|c|c|c|c|c|c|c|}
\hline & & (1) & (2) & (3) & (4) & (5) & (6) & (7) \\
\hline \multirow[t]{3}{*}{ Blau_prof $(t-1)$} & Coef & $1.401^{* *}$ & 2.942 & 2.921 & $1.366^{* *}$ & $2.004 *$ & $1.964 *$ & 1.811 \\
\hline & SE & $(0.676)$ & $(2.125)$ & $(2.123)$ & $(0.681)$ & (1.107) & (1.124) & (1.104) \\
\hline & Margin & 0.0384 & 0.166 & 0.169 & 0.0451 & 0.0702 & 0.0804 & 0.101 \\
\hline \multirow[t]{3}{*}{ Blau_prof_square $(t-1)$} & Coef & & -2.204 & -2.240 & & & & \\
\hline & SE & & $(2.845)$ & $(2.812)$ & & & & \\
\hline & Margin & & 0.439 & 0.426 & & & & \\
\hline \multirow[t]{3}{*}{$O S(t-1)$} & Coef & & & 0.0283 & 0.0210 & 0.193 & 0.229 & 0.236 \\
\hline & SE & & & $(0.122)$ & $(0.122)$ & $(0.298)$ & $(0.296)$ & $(0.296)$ \\
\hline & Margin & & & 0.816 & 0.864 & 0.517 & 0.439 & 0.424 \\
\hline \multirow[t]{3}{*}{ Blau_prof*OS $(t-1)$} & Coef & & & & & -0.386 & -0.447 & -0.417 \\
\hline & SE & & & & & $(0.550)$ & $(0.543)$ & $(0.538)$ \\
\hline & Margin & & & & & 0.482 & 0.411 & 0.438 \\
\hline \multirow[t]{3}{*}{ log_size } & Coef & & & & & & 0.0433 & -0.0412 \\
\hline & SE & & & & & & $(0.191)$ & $(0.198)$ \\
\hline & Margin & & & & & & 0.820 & 0.835 \\
\hline
\end{tabular}




\begin{tabular}{|c|c|c|c|c|c|c|c|c|}
\hline \multirow[t]{3}{*}{$F D I(t-1)$} & Coef & & & & & & 0.420 & 0.331 \\
\hline & SE & & & & & & $(0.475)$ & $(0.463)$ \\
\hline & Margin & & & & & & 0.376 & 0.475 \\
\hline \multirow[t]{3}{*}{$\log \_a g e$} & Coef & & & & & & 0.380 & $0.419^{*}$ \\
\hline & SE & & & & & & $(0.231)$ & $(0.236)$ \\
\hline & Margin & & & & & & 0.100 & 0.0757 \\
\hline \multirow[t]{3}{*}{ Export $(t-1)$} & Coef & & & & & & $-0.00943 *$ & -0.00751 \\
\hline & SE & & & & & & $(0.00527)$ & $(0.00525)$ \\
\hline & Margin & & & & & & 0.0732 & 0.153 \\
\hline \multirow[t]{3}{*}{ machinery } & Coef & & & & & & & -0.752 \\
\hline & SE & & & & & & & $(0.606)$ \\
\hline & Margin & & & & & & & 0.214 \\
\hline \multirow[t]{3}{*}{ textiles } & Coef & & & & & & & -0.795 \\
\hline & SE & & & & & & & $(0.551)$ \\
\hline & Margin & & & & & & & 0.149 \\
\hline \multirow[t]{3}{*}{ wood } & Coef & & & & & & & -0.408 \\
\hline & SE & & & & & & & $(0.596)$ \\
\hline & Margin & & & & & & & 0.494 \\
\hline \multirow[t]{3}{*}{ chemical } & Coef & & & & & & & -0.387 \\
\hline & SE & & & & & & & $(0.473)$ \\
\hline & Margin & & & & & & & 0.413 \\
\hline \multirow[t]{3}{*}{ metallurgy } & Coef & & & & & & & 0.996 \\
\hline & SE & & & & & & & $(1.051)$ \\
\hline & Margin & & & & & & & 0.343 \\
\hline \multirow[t]{3}{*}{ others } & Coef & & & & & & & -0.646 \\
\hline & SE & & & & & & & $(0.653)$ \\
\hline & Margin & & & & & & & 0.323 \\
\hline \multirow[t]{3}{*}{ Food (omitted) } & Coef & & & & & & & - \\
\hline & SE & & & & & & & \\
\hline & Margin & & & & & & & - \\
\hline Observations & & 469 & 469 & 469 & 469 & 469 & 469 & 469 \\
\hline Cases & & 329 & 329 & 329 & 329 & 329 & 329 & 329 \\
\hline
\end{tabular}


Figure 1. Educational workforce diversity. kernel density distribution of Blau_prof index

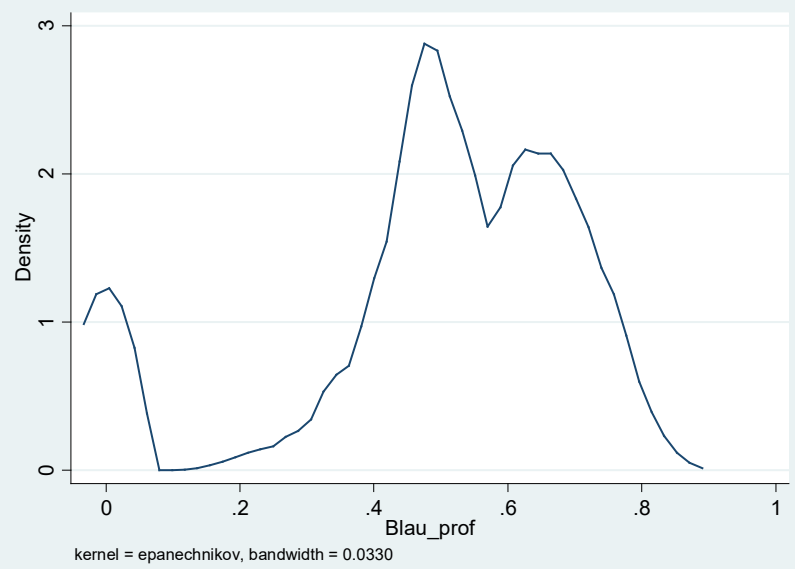

Source: Authors' calculation based on UIIS data 